\title{
O “amor" pela Música, um Dicionário e a Cultura Musical como Pedagogia no século XIX
}

\author{
The "love" for Music, a Dictionary and de Musical \\ Culture as Pedagogy in the $19^{\text {th }}$ century
}

GILBERTO VIEIRA GARCIA (iDa

\section{Resumo}

O objetivo deste artigo é apresentar uma perspectiva da História da Educação Musical que se desenvolve, para além das instituições escolares, especificamente, no campo da Cultura. A questão central será tentar compreender como o campo da Cultura Musical pode operar também como "Pedagogia", tendo como recorte o século XIX. O objeto de estudo que dará suporte a essas reflexões será o "Dicionário Musical", de Raphael Coelho Machado, publicado no Brasil em 1842. Para tanto as referências teóricas utilizadas abrangem as categorias de "programa institucional" (Dubet, 2002), "regime de amadorismo" (Fauquet e Hennion, 2000) e "cultura como pedagogia" (Silva, 2005). Como conclusão geral deste artigo, constata-se que os processos históricos de constituição e afirmação de determinadas Culturas Musicais apresentam-se como uma importante temática para ser problematizada e estudada também dentro da área da História da Educação Musical.

Palavras-chave: Cultura como pedagogia. História da Educação. História da Educação Musical. História da Música no Brasil. Música no Brasil Império.

\section{Abstract}

The objective of this article is to present a study perspective of the History of Musical Education focused on the field of Culture and not directly on school institutions. The central question will be to try to understand how the field of

\footnotetext{
a Instituto Federal Fluminense (IFF), Itaperuna, Rio de Janeiro, Brasil e Centro de Estudos de Sociologia e Estética Musical/Universidade Nova de Lisboa (CESEM), Lisboa, Portugal. Doutor em Educação, e-mail: Gillberto.vieira@gsuite.iff.edu.br 
Musical Culture can also operate as "Pedagogy", during the period of the 19th century. The object of study that will support these reflections will be the "Musical Dictionary", by Raphael Coelho Machado, published in Brazil in 1842. For this purpose, the theoretical references used are the categories of "institutional program" (Dubet, 2002), "regime of amateurism "(Fauquet and Hennion, 2000) and" culture as pedagogy "(Silva, 2005). The general conclusions of this article are to verify that the historical processes of constitution and affirmation of certain Musical Cultures are presented as an important topic, also, to be studied within the area of History of Musical Education.

Keywords: Culture as pedagogy. History of Education. History of Music Education. History of Music in Brazil. Music in the Empire of Brazil.

\section{Resumen}

El objetivo de este artículo es presentar una perspectiva de la Historia de la Educación Musical que se desarrolla más allá de las instituciones escolares, específicamente en el campo de la Cultura. La cuestión central será intentar comprender cómo el campo de la Cultura Musical puede operar también como "Pedagogía", tomando como recorte temporal el siglo XIX. El objeto de estudio que dará soporte a esas reflexiones será el "Diccionario Musical" de Raphael Coelho Machado, publicado en Brasil en 1842. De esta manera, las referencias teóricas utilizadas consideran las categorías de "programa institucional" (Dubet, 2002), "régimen amateur" (Fauquet e Hennion, 2000) y "cultura como pedagogía" (Silva, 2004). Las conclusiones generales de este artículo están en constatar que los procesos históricos de constitución y afirmación de determinadas Culturas Musicales se presentan como un tema importante, también, para ser estudiado dentro del área de Historia de la Educación Musical.

Palabras clave: Cultura como pedagogía. Historia de la Educación. Historia de la Educación Musical. Historia de la Música en Brasil. Música en el Imperio de Brasil.

In a sense, language is conception, and conception is the frame of perception (Suzanne Langer).

\section{Introdução}

O propósito geral deste texto é tentar promover uma reflexão introdutória sobre a importância de se pensar sobre o papel que determinas culturas musicais vêm exercendo, historicamente, como instituições pedagógicas, constituindo-se, assim, como objetos de estudo que devem ser também analisados e problematizados dentro da área da História da Educação Musical, em conjunto com as demais instituições de 
ensino e aprendizagem musical. Este ensaio configura-se como um desdobramento de outros trabalhos de pesquisa que trataram da institucionalização do ensino de música no Rio de Janeiro, no século XIX (GARCIA, 2014 e GARCIA, 2018), preservando o mesmo recorte temporal assumido nos referidos trabalhos, transferindo, porém, o foco das análises dos estabelecimentos formais de ensino e das trajetórias docentes neles priorizados, para o aprofundamento de algumas reflexões mais específicas sobre o papel da "cultura musical como pedagogia" neste contexto delimitado.

Para isso, o texto está divido em quatro seções centrais, além das conclusões e das considerações finais. Na primeira seção, será brevemente apresentada a categoria de "programa institucional", desenvolvida pelo sociólogo François Dubet (2002), em um trabalho no qual o autor analisa a ascensão e o declínio da escola moderna, procurando compreender aqui a sua operacionalidade dentro do campo da História da Educação Musical. A segunda e terceira seções, onde será discutida a categoria de "regime de amadorismo" e o seu papel na consolidação histórica daquilo que passou a ser consagrado como "A grande música", conforme definido pelo sociólogo Antoine Hennion e pelo musicólogo Jöel-Marie Fauquet (2000), em um estudo dedicado a compreender o "amor" a determinados tipos música como um sentimento construído historicamente. Nessas seções, serão abordados alguns elementos desse processo histórico, bem como determinados suportes e instituições que fizeram parte do seu desenvolvimento e afirmação, incluindo-se entre eles, o mercado editorial, a publicação de métodos e manuais e, em termos gerais, próprio campo do ensino formal de música. Concluindo a parte central do texto, está a quarta seção onde serão realizadas reflexões com uma base mais empírica, visando compreender historicamente o lugar de determinadas culturas musicais como pedagogia, a partir da análise de alguns verbetes do Dicionário Musical de Raphael Coelho Machado, publicado no Rio de Janeiro, em 1842.

A articulação entre as reflexões desenvolvidas em cada uma das partes será fundamentada a partir da discussão promovida por Tomaz Tadeu da Silva sobre "a pedagogia como cultura" e "a cultura como pedagogia", no seu clássico livro Documentos de identidade: uma introducão às teorias do currículo (2005). Como destaca o autor, o movimento da "virada culturalista" iniciado no começo da década de 1970 
influenciou fortemente o campo de estudos do currículo escolar, chamando a atenção para os pontos de contato, interseção e equivalências entre o conhecimento acadêmico escolar e o conhecimento do cotidiano e da cultura de massas. Nessa perspectiva, considerando-se que todo conhecimento, enquanto um sistema de significação, é cultural, ganham relevo as análises sobre o papel formativo exercido por instâncias, instituições e processos culturais aparentemente diversos, como, por exemplo, museus, filmes, televisão, publicidade, artes visuais e música. Como consequência, se o conceito de "cultura" de alguma forma torna possível equiparar a educação a outras instâncias culturais, o conceito de "pedagogia" possibilita realizar a operação inversa; permitindo afirmar então que, assim como a educação, as demais instâncias culturais são também pedagógicas e, portanto, ensinam também alguma coisa. A partir disso, considerando que tanto a educação quanto a cultura em geral estão envolvidas em processos formativos, a cultura em geral pode ser compreendida também como uma pedagogia, da mesma forma em que a pedagogia pode ser reconhecida como uma instância cultural, tornando possível aproximar assim os sistemas escolares aos sistemas culturais extraescolares. Uma perspectiva de análise fundamental para a elaboração deste ensaio, tendo em vista realizarmos um exercício de reflexão sobre "a cultura musical como pedagogia" e "a pedagogia musical como cultura", na perspectiva da História da Educação Musical.

\section{Do programa institucional à "Grande Música”}

Preocupado em aliar uma sociologia do trabalho a uma sociologia da socialização, François Dubet (2002) analisa a prática docente como uma das atividades centrais da modernidade, dentre aquelas que visam explicitamente transformar o outro, atuando de modo objetivo sobre as suas condutas, sentimentos, valores e representações individuais e coletivas. De acordo com o autor, esse tipo de trabalho deve ser compreendido como um programa institucional que se configura como um modo de socialização e um tipo de relação sobre o outro, ambos de caráter específico, sendo percebido, por exemplo, a partir do vínculo funcional estabelecido entre os papeis de professor e aluno, bem como da definição de cada um desses papeis. De acordo com Dubet, o programa institucional tem como fundamento: 
1) que o trabalho sobre o outro é um mediação entre os valores [e saberes] universais e os indivíduos particulares; 2) que o trabalho de socialização é uma vocação porque está diretamente informada sobre tais valores e [saberes]; 3) que essa socialização visa inculcar as normas que conformam o indivíduo e, ao mesmo tempo, o torna autônomo e "livre" (DUBET, 2002, p. 13-14).

Nesse sentido, o modelo de instituição escolar consolidado no século XIX ocupa um espaço central nas análise do autor, ao afirmá-la historicamente como um santuário do saber (monumento supostamente "protegido" contra as "desordens" do mundo e às "paixões humanas"), consagrado, por sua vez, por meio da vocaşão do seu corpo docente e da afirmação da sua autoridade profissional para o exercício do trabalho educativo, que foi endossada a partir desse período, sobretudo, pelo Estado e o desenvolvimento da instrução pública (NÓVOA, 1992). Essa vocação e essa autoridade eram atestadas a partir do reconhecido domínio que os docentes deveriam demonstrar possuir sobre os princípios "universais" de suas matérias e áreas de conhecimento, o que, no caso específico da arte dos sons compreende o domínio sobre linguagem, o repertório e as práticas associadas àquilo que passou a ser afirmado, em termos socioculturais e históricos, como "A Grande Música".

\section{Da "Grande Música" ao "Regime de amadorismo"}

Em termos específicos, foi durante o século XIX que as discussões sobre os valores estéticos e as funções éticas da música ganhariam mais uma vez na história ${ }^{1}$ um forte impulso, diante das preocupações para que fossem instituídos critérios e instrumentos que permitissem definir e mensurar o que deveria ser considerado, então, como "A grande Música". Nesse sentido, duas mudanças fundamentais ocorreram de maneira conjunta na cultura musical ao longo do século XIX. Uma delas foi a construção da ideia de música "clássica" atrelada a um conjunto seleto de compositores e obras do passado que seria compreendido, cada vez mais, como algo exemplar, dotado de valores absolutos, como algo sagrado, canônico. A outra mudança foi a atualização da hierarquização dos gostos que viria a estabelecer uma distinção entre a música reconhecida como "séria" e respeitável e aquela estigmatizada como "ligeira" - dentro de um contexto de desenvolvimento de um mercado de lazer

\footnotetext{
${ }^{1}$ Questões que, por diferentes motivos e perspectivas de argumentação, vem sendo debatidas ao longo da história da música ocidental, desde a antiguidade, como demonstram, por exemplo, Enrico Fubini (2008) e Ludia Goehr (2007). 
e entretenimento. Um sistema de posições hierárquicas no qual, de um lado, se posicionavam os defensores de uma corrente artística considerada como profunda, rigorosa, perene e, portanto, de alta cultura; e, do outro, uma tendência mais "popularesca", considerada como de fácil acesso, fortuita, superficial, associada às distrações vãs e às modas passageiras.

Como destaca Menger, foi dentro desse complexo ambiente de transformações referentes ao fomento, à oferta, às demandas musicais e as suas distintas categorizações, que passaria a se afirmar, de maneira exponencial, um individualismo artístico, "armado por toda uma aparelhagem ideológica que visava, notadamente, celebrar os méritos incomensuráveis do talento excepcional, do gênio" (MENGER, 2009, p. 369). Por meio dos estudos biográficos dos autores e da incansável e minuciosa exegese de suas obras, foi a partir desse viés que a figura do compositor, seus dotes de criação e sua grandeza, vieram a ocupar uma posição central na construção da história, na definição dos dispositivos necessários para uma apreciação e uma prática musical "legítimas", bem como na defesa dos pressupostos que deveriam ser tomados como base para o "verdadeiro" progresso e futuro da música, desde seu ensino e aprendizagem até a suas formas de apreciação e meios de celebração.

Fauquet \& Hennion, ao trabalharem sobre a proposição do "amor pela música como uma produção histórica", afirmam que a "musicalização" do nosso gosto, isto é, “a formação de competências específicas, de mais em mais definidas, internalizadas e incorporadas", que nos fez apreciar em alguma medida um determinado conjunto de obras e celebrar a genialidade de seus compositores, constitui-se, segundo a denominação dos autores, como um "regime de amadorismo" - um regime ao qual, de maneira natural e íntima, "nós não vemos mais como e quando que lhe pertencemos" (FAUQUET \& HENNION, 2000, p. 20).

A partir dessa proposição, de acordo com os autores, "o amador não seria simplesmente um imitador do músico de carreira”, mas, sim, alguém que pretende desenvolver de modo cada vez mais autônomo o gosto pela música, procurando encontrar nela, e em todas as suas prática derivadas, o mais profundo e autêntico prazer estético (Idem, p. 196). Para mais ou para menos, sobretudo no contexto do século XIX, essa procura compreendia, por exemplo, o auto-preparo antes de uma 
audição; o aprimoramento das competências necessárias para tocar as obras, após uma longa e árdua aprendizagem individual ou coletiva; o conhecimento da história dos compositores e da evolução dos diversos estilos e suas características; e, especialmente, o apreço por uma cultura reflexiva do gosto e das obras "difíceis", em nome dos "estados provocados pelos objetos aos quais" se, por um lado, "a apreciação é problemática”, por outro, como recompensa, “o deleite é sublime” (Idem, p. 206).

Ainda segundo os autores, "longe de poder opor o amadorismo ao profissionalismo, é preciso reconhecer que esse último não pode plenamente se desenvolver senão dentro de um tal regime" (Idem, p. 196). Nessa perspectiva, deixa de fazer sentido uma concepção negativa do trabalho com a música estritamente como uma prestação de serviço que, como tal, se restringiria ao cumprimento de um conjunto pré-determinado de funções atreladas, por exemplo, ao calendário e aos rituais da Igreja e do Estado, tais como nascimentos, aniversários, casamentos ou as comemorações de eventos considerados importantes nessa esfera. Justamente ao contrário, é procurando dar à música um estatuto próprio, transcender esses limites funcionais, afirmar o seu poder como um trabalho criativo e propagar os seus valores como uma prática individual ou coletiva de autodesenvolvimento, que essa rede de amadores irá realizar e retroalimentar todo um empreendimento de construção, de manutenção e de evolução desse regime específico de cultivo e amor à música.

Entretanto, esse "regime de amadorismo" ganha um sentido particular para se pensar sobre as questões que envolveriam a sua difusão e a sua consolidação dentro do contexto específico da sociedade brasileira oitocentista. Uma sociedade escravocrata, onde, a música era não apenas largamente concebida como uma "arte de artesão"2, mas, também, como uma atividade prática e, sobretudo, como um ofício destinado aos cativos e aos demais extratos sociais desprestigiados. Condições essas que se constituirão como um dispositivo sociocultural de difícil transposição diante dos interesses e das possibilidades para difundir esse "regime de amadorismo" no Brasil, valendo-se dos seus aspectos formais e dos seus conteúdos específicos, tendo como propósito promover uma certa valorização artística da música, favorecendo,

\footnotetext{
${ }^{2}$ Ver ELIAS (1992).

Rev. Caminhos da Educação: diálogos, culturas e diversidades, Teresina, v. 3, n. 1, p. 53-73, Jan./Abr. 2021
} 
assim, a sua concepção como um trabalho livre e/ou como uma prática "ilustrada" e de desenvolvimento cultural e civilizacional.

Em termos gerais, dentro dessa empreitada, segundo Fauquet e Hennion (2000), os primeiros amadores foram os próprios músicos profissionais, que, atuando como mediadores, passaram a exercer um papel destacado nesse processo que instituiu em torno da música "clássica" uma aura que a distingue como "um objeto de degustação elaborada". Fundamentalmente, foram os próprios músicos que, “inventando, modificando e desenvolvimento, por sua vez, os repertórios, as concepções, as competências, os suportes e as instituições”, se investiram da sua capacidade e da sua propriedade de satisfazer com música os desejos musicais cada vez mais criteriosos, específicos, hierárquico e distintos. O que tornou imprescindível a necessidade de atuação nos campos do ensino e da aprendizagem, da composição, da editoração de partituras e métodos, da realização de concertos públicos e privados e da crítica musical (FAUQUET e HENNION, 2000, p. 197).

\section{Do “Regime de amadorismo” aos suportes e instituições}

Pensando a partir do contexto europeu, Fauquet e Henion (2000) não deixam de frisar a importância que os quadros materiais e institucionais tiveram junto ao processo de consolidação do "regime de amor à música", servindo como suporte e como meio para difundir e compartilhar socialmente a "apreciação estetizante" e os “objetos" que lhes seriam concernentes. Desses quadros, devem ser destacados, sobretudo, os concertos públicos; a crítica especializada; o comércio de partituras, coleções, arranjos e livros dedicados aos amadores; e, em especial, o crescente uso pedagógico desses impressos musicais pelos professores particulares, bem como por aqueles atuantes nos conservatórios e também nas instituições de ensino primário e secundário.

Quanto ao suporte, sem sombra de dúvida, o desenvolvimento da tipografia e a estabilização do sistema notacional e de suas convenções tiveram um papel fundamental nesse processo, a partir de quando a transmissão manuscrita perdera gradativamente o seu domínio e a sua exclusividade. Ao longo da segunda metade do século XVIII, a imprensa musical já se constituía como um segmento econômico que 
extrapolava as tradições nacionais, regionais e locais, em proveito de modos de notação mais simples, haja vista a impressionante intensificação do comércio de partituras, de tablaturas e dos métodos de ensino de música.

Como demonstra em detalhes Sylvie Bouissou (2005), nessa nova etapa, diante da necessidade de um certo "universalismo", foi preciso codificar a notação em termos mais homogêneos, pois, no mesmo momento em que ocorria a sua difusão em grande escala, "a música tornava-se cada vez mais europeia”. Afirmação que ganha sentido ao se considerar, por exemplo, o tonalismo, o temperamento, a definição de uma afinação oficial, a padronização das variações de velocidade com o metrônomo, bem como o estabelecimento de critérios modelares de coerência formal, estilística e estrutural - pressupostos que, inicialmente, viriam a se tornar comuns entre os países europeus e que, rapidamente, se propagariam pelo mundo - incluindo o Brasil.

Outro fator central na consolidação desse "regime de amadorismo" foi a atuação dos músicos dentro do campo do ensino público, tomando como instituição de referência os conservatórios e a sua maneira particular de transmitir a música. $\mathrm{O}$ que, em certa medida, se estabeleceu como uma espécie de modelo "universal", tendo como base o emprego de métodos racionais; de modos de trabalho e de avaliação sistemáticos (como exames e concursos); de técnicas instrumentais e vocais definidas; além da remissão obrigatória a determinados compositores e obras do passado considerados como "canônicos" e, portanto, essenciais para o desenvolvimento dos mais apurados critérios ou claves de apreciação, de performance e de criação musical.

Rémy Campos (2016) ao realizar um ensaio sobre o Conservatório de Paris, analisando a sua história, a sua estrutura institucional e, de certo modo, o seu papel na consolidação de um "sistema conservatorial" na França como um todo, afirma que a sua constituição como um modelo foi tão forte que, de diferentes formas, extrapolou os próprios limites do país. O que, segundo o historiador, pensando no contexto europeu e nas principais reformas educacionais que ocorreram durante o século XIX, pode ser compreendido a partir de três pontos. Em primeiro lugar, a intervenção do Estado nas "instituições modernas de ensino de música”, impondolhes um caráter público e de formação profissional. Em segundo, "uma concepção total de ensino", reunindo dentro de uma mesma instituição o conjunto de saberes musicais considerados essenciais, organizados e sequenciados como "cursos 
obrigatórios". E, em terceiro, o desenvolvimento do ensino coletivo em classes e a publicação de métodos oficiais (CAMPOS, 2016, p. 72).

Paralelamente a esse sistema voltado sobretudo para a formação de profissionais e virtuoses, é necessário considerar também a importância que o ensino de música assumirá nesse contexto, como parte de uma formação geral, englobando tanto o campo da "instrução pública", quanto diferentes associações e agremiações amadoras, tendo como um de seus principais expoentes o compositor e pedagogo francês Boucquillon-Wilhem (1781-1842) - responsável por desenvolver o que ele mesmo denominou como música de “orfeão". Dentro desse domínio, como afirma Philippe Gumplowicz (1987), para o músico-pedagogo francês:

$\mathrm{O}$ verdadeiro artista seria aquele que faz cantar a alma do povo. Tudo deve girar em torno desse objetivo. Para alcançá-lo, é preciso se guardar de todas as extravagâncias, se manter na realidade, evitar uma grande sofisticação, fugir da vulgaridade. Ser simples. Ter a grande coragem da simplicidade (p. 22).

O seu foco, a princípio, dirigiu-se inicialmente apenas às crianças e ao ensino primário. O seu pressuposto básico consistia na necessidade de ensinar música considerando-a como uma língua. Diante disso, a primeira coisa a ser feita seria, então, ensinar os alunos a ler, a escrever e a conhecer os princípios elementares de sua gramática (Idem, p.26). Para tanto, imerso em um intenso contexto de discussão sobre educação e, também, sobre o ensino de música, Wilhem desenvolveu a sua própria metodologia que, tendo como inspiração os "métodos mutualistas", compreendia: a divisão da turma em oitos grupos; a escolha de alunos que seriam responsáveis por cada grupo; e a confecção de quadros visuais destinados a dar mais visibilidade aos conteúdos e a "torná-los mais atraentes" (Idem, p. 26). Com base nesse método, em 1821, foi publicada a primeira edição dos Tableaux pégagogiques de la méthode Wilhem. Publicação que se espalhou desde então por toda a França, tornando-se a base de ensino de inúmeras escolas e associações amadoras, envolvendo crescentemente a participação dos seus alunos em eventos públicos, sobretudo, cívicos, que chegaram a reunir milhares de cantores (GUMPLOWICZ, 1987). Esse movimento alcançou uma enorme importância ao longo do século XIX até meados do século XX, influenciando diversos outros países dentro e fora da Europa, incluindo o próprio Brasil Império (GARCIA, 2018). 


\section{Do “amor” pela Música ao Dicionário como um estatuto}

A publicação de enciclopédias, tratados e dicionários é uma prática que se dissemina com muita força nos séculos XVIII e XIX, abrangendo diversos ramos do saber. Pensando estritamente nos dicionários, Allen (1962) afirma que o simultâneo aparecimento de trabalhos classificatórios em vários campos, nesse período, pode indicar algo mais do que coincidência, principalmente por ter como base um mesmo "tipo atomístico de filosofia e investigação", isto é, um conjunto de teorias que procuravam particularizar os elementos da análise, para construir a concepção de um todo (ALLEN, 1962, p. 63). Um tipo de perspectiva epistemológica que se configura, por exemplo, na produção de taxionomias e verbetes cuja articulação visava poder explicar um determinado ramo do saber, em sua totalidade - no caso, a música.

Como explicita Nunes (2010), em termos analíticos, não se devem perder de vista nem as "condições de produção de discurso" sob às quais um dicionário é elaborado, nem os "sujeitos lexicográficos" que elaboram os dicionários e as situações em que eles se inserem - fatores que interferem nos "sentidos das palavras selecionadas e definidas, bem como no direcionamento geral dessa prática" (NUNES, 2010, p. 7). É a partir dessas considerações que será feita uma análise de alguns verbetes do Dicionário Musical publicado em 1842, por Raphael Coelho Machado prestigiado instrumentista, compositor e também editor e professor que atuou em alguns dos principais espaços e meios de "circulação cultural" do município da Corte, no Rio de Janeiro, entre as décadas de 1840 e 1870. Um membro destacado da sociedade dos músicos na Capital do Império, premiado com o título de Cavaleiro da Imperial Ordem da Rosa, fundador e redator do primeiro periódico no Brasil dedicado exclusivamente a publicação de partituras (o Ramalhete da Damas, 1842-1856), sócio honorário e benemérito de varias sociedades artísticas, literárias e de beneficência que, além disso, atuou ativamente no campo da educação, realizando várias publicações sobre teoria e prática musical ${ }^{3}$ e também ocupando o cargo de professor de harmonia e instrumentação no Imperial Instituto dos Meninos Cegos.

\footnotetext{
${ }^{3}$ Princípios de Música Prática (1842), Breve tratado de Harmonia (1851), Método de Órgão Expressivo (1852), entre outras, incluindo-se também o próprio Diccionario Musical (1842). 
Ainda de acordo com Nunes (2010), além de visar ao conhecimento específico de uma ou mais línguas, fazer dicionário serve, dentre outras coisas, para três fins: entrar em contato com uma sociedade ou cultura desconhecida, ou que se tem informações pouco sistematizadas; participar da construção de identidades (nacionais, regionais ou de grupos); e, ainda, conhecer e produzir conceitos utilizados em certas áreas das ciências e das artes. Finalidades que se mostram pertinentes para se pensar sobre a produção desse dicionário como parte dos projetos desenvolvidos no Brasil do século XIX votados, direta ou indiretamente, para a institucionalização do ensino de música. O que englobaria desde a consolidação do modelo conservatorial, passando pela afirmação do seu espaço e das suas funções junto à instrução primária e secundária, chegando até uma dimensão mais difusa que compreende as tentativas de definir a seu estatuto como linguagem, determinando significados e formas de compreensão.

De acordo com Dubet (2002), considerando que a amplitude de fenômenos e fatos sociais designados pelo termo "instituição" lhe possibilita um leque de empregos que variam de acordo com diversos contextos e argumentações, é importante delimitar seus significados em face de sua operacionalidade junto à categoria "programa institucional". Preocupado com a abrangência da ideia de que as instituições, segundo Durkheim, seriam todas as crenças e condutas instituídas pela coletividade, Dubet afirma que, para além dos "fatos" e das práticas coletivas, as instituições devem ser compreendidas também como "quadros cognitivos e morais dentro dos quais se desenvolvem os pensamentos individuais" (DUBET, 2004, p. 22). Ideia que se conclui com a afirmação de que a língua seria a primeira das instituições, por estar associada a modos de conhecimento que, por sua permanência, seriam compatíveis com as experiências não apenas individuais e, mas, sobretudo, coletivas. Uma perspectiva interessante, portanto, para estabelecer uma relação entre a institucionalização da música e do seu ensino e as preocupações em definir e afirmar a sua essência enquanto uma linguagem e um modo de conhecimento específico.

Ao analisar o dicionário tal questão torna-se evidente quando, por exemplo, Raphael Coelho Machado apresenta uma definição linguístico-gramatical da música extremamente detalhada e objetiva, como se observa no seguinte verbete: 
LINGUA MUSICAL. A musica considerada como língua tem seus princípios elementares, sua ortografia, sua pontuação, prosódia, frases, períodos, ritmos, proposições, cadências, em uma palavra, sua gramatica, poesia e retorica; pode-se por consequência ler, recitar e declamar musica como qualquer outra língua [...]. (MACHADO, 1855, p. 107)

Uma preocupação que, de certo modo, demonstra ter também uma razão de ordem política, tanto, em termos gerais, posta pelo próprio ato de publicar um dicionário, definindo vocabulários, conceitos e significados, sintetizando assim um pensamento estético-musical ideal; quanto, em termos específicos, ao trazer como questão a necessidade de compreender a música como uma língua, afirmando o seu caráter gramatical e, portanto, normativo, como pode ser percebido no seguinte verbete:

GRAMMATICA MUSICAL é o resumo das regras que ensinam a dispor e combinar os sons e os acordes. Uma peça de musica, trabalhada segundo as regras gramaticais, denomina-se peça regular, correta. [...] Os erros gramaticais em musica ferem tanto a inteligência e o ouvido do conhecedor, e perturbam tanto o sentimento do puro prazer que se experimenta em uma obra d'arte, como as faltas gramaticais em poesia. - V. Lingua musical (p. 78-79).

Nessa perspectiva, para além de quaisquer aspectos positivos que possam ser destacados, o domínio da escrituração musical passa a exercer também uma função central na qualificação e na hierarquização das identidades e das práticas musicais, valorizando certas habilidades específicas, normatizando práticas e formas de execução, legitimando determinados critérios de estruturação, compreensão e expressão musical. Questão que fica bastante clara, por exemplo, no verbete MUSIQUIM:

(dim. e pejorativo de musico), musico ambulante ou musico inepto que, limitado ao conhecimento das notas e dos caracteres musicais, e habituado á medida, executa com desembaraço, mas sem sentimento, sem gosto e sem expressão, e que ferindo apenas os sons escritos, não compreende nada do que diz. is șp̣Também é aplicável aos músicos que, familiarizados pela pratica em as harmonias singelas e quais naturais, se enxertam em compositores com igual fundamento ao daquele, que apenas sabendo ler, escreve um discurso sem todavia poder ao menos definir o que seja gramatica e retorica (p. 129-130).

Nesse verbete o que se percebe é uma tentativa de estabelecer um distinção profissional entre o "Músico" e o "Musquim”, se assumindo como princípio a noção de que dominar a escrituração e ter fluência nesta linguagem musical implicaria, necessariamente, em transcender o uso "inconsciente" e "mecânico" das notas e de seus caracteres, bem como a sua função enquanto um "simples" saber "aplicado" e de caráter "utilitário". Para além desse estágio "superficial", a diferença deveria ser afirmada e identificada, sobretudo, pelo domínio dos conhecimentos em harmonia e composição, suas "regras gramaticais e retóricas" e, especialmente, o que isso 
resultaria em termos de consagração de determinados padrões estéticos e critérios de criação, de execução e de fruição e cultura musical.

Para tornar ainda mais completa e precisa essa distinção identitária o autor apresenta ainda a categoria dos "AMADORES", que são definidos em um verbete próprio como aqueles que "amam, se deleitam ou gostam de uma coisa com preferência às outras; musicalmente significa: amantes, e apaixonados da Musica, que a estudam, e exercitam pelo prazer, que nela encontrão, sem fazerem disso ocupação: vulgarmente, curiosos" (Idem, p.6, grifo do autor). Categoria que se mostra interessante para se perceber que, mesmo por curiosidade ou diletantismo, esse "sentimento", essa "paixão" e essa "forma de amor à música", para torna-se plena, por princípio, não deveria prescindir dos estudos e dos exercícios pertinentes, tendo como base, para tanto, a aprendizagem da escrituração musical.

Compreendidos a partir de uma perspectiva política, a preocupação e o cuidado com o estabelecimento desses critérios de distinção se tornam ainda mais evidentes ao tentar compreendê-los como uma forma de resposta ao processo de transformação do cenário musical que se intensificará notadamente a partir das primeiras décadas do Segundo Reinado (1840-1889), quando o mercado de entretenimento começou a se estruturar de maneira mais intensa, no contexto da cidade do Rio de Janeiro (ALENCASTRO, 2008; MELO, 2014). Tal processo de transformação, dentro do qual a música passará a assumir cada vez mais uma diversidade de funções e de lugares, pode ser observado, por exemplo, a partir do crescimento da oferta de óperas e concertos; da disseminação das práticas diletantes em inúmeras sociedades musicais (MAGALDI, 1995); do crescimento das publicações voltadas para o "mundo da música"; ou, ainda, pelo aumento do número de professores particulares (GARCIA, 2018) e da comercialização de instrumentos, especialmente, do piano - um dos símbolos de distinção dos membros da "boa sociedade" (AMATO, 2007). Entretanto, como parte de um contexto marcado também pela efervescência de novas modas e de hábitos e comportamentos considerados efêmeros e superficiais, essas transformações não deixaram de ser percebidas com suspeição e, mesmo, recusa, sobretudo, naquilo em que pudessem representar enquanto um indício de corrupção dos "bons costumes" e, particularmente, de ameaça à consolidação de um "regime de amadorismo" no país e seus preceitos de valorização sociocultural da música. O que 
já vinha sendo duramente criticado por Manuel Araújo Porto Alegre ${ }^{4}$, ainda no período Regencial (1831-1840), quando afirmava no referido ensaio publicado na revista Nytheroi que:

O retrato icônico de uma sociedade corrupta é a moda; o delírio, e a extravagancia passeiam nas salas dos bailes personificados na casava ou toucado, e o pior é, que os homens sensatos estão sujeitos a essa lei, para não desatarem o riso do estúpido casquilho, ou da senhora de bom tom, que, separados da sociedade humana, da sociedade intelectual, só prestam obediência à autoridade do cabeleireiro, alfaiate, ou modista (PORTO ALEGRE, 1836, p. 176).

A partir dessa perspectiva, o processo de ampliação da presença da música e de suas práticas junto à "boa sociedade" do Rio de Janeiro, quando associado diretamente ao mercado de entretenimento, era então percebido também pelo seu potencial para comprometer e desvirtuar determinadas finalidades estéticas e a própria "natureza" ético-pedagógicas da música, tão primordiais para a formação das sensibilidades, das percepções e do "bom gosto", bem como para o cultivo de comportamentos e de hábitos considerados como civilizados. É importante mencionar o quanto essa discussão ainda está atrelada a uma concepção musical que fora desenvolvida a partir do pensamento pitagórico e platônico, a partir de onde se estabelece uma fratura entre uma música “especulativa”, valorizada em seus aspectos teóricos, filosóficos, racionais e "científicos", e uma outra meramente sensorial e prática que, por seus efeitos "superficiais" e sua função imediata de servir apenas como passatempo, deveria ser, portanto, desprezada (FUBINI, 2008).

Nesse sentido, chama a atenção o papel que passará a ser atribuído à teoria musical e, especialmente, à "educação estética", enquanto fatores determinantes para a fundamentação dessa "concepção fraturada" e, mesmo, do próprio "regime de amor à música". O que pode ser percebido no verbete "TEORIA-MUSICAL", onde a definição apresentada por Raphael Coelho Machado a concebe a partir de uma ordem

4 Manuel Araújo Porto Alegre (1806-1879) foi importante pintor, arquiteto e caricaturista; escritor e periodista; professor, crítico e "historiador" da arte; estando entre os fundadores da revista Nitheroy (considerada o marco inicial do romantismo no Brasil), além de ter sido professor e diretor da Academia Imperial de Belas Artes, professor de desenho do Imperial Colégio Pedro II e orador do Instituto Histórico e Geográfico Brasileiro (SQUEFF, 2004). Destacando-se, especificamente, como um importante intelectual que contribui com o desenvolvimento da institucionalização do ensino de música no Rio de Janeiro, no século XIX, sobretudo, pelo projeto de vinculação do Conservatório de Música à Academia Imperial de Belas Artes (GARCIA, 2019).

Rev. Caminhos da Educação: diálogos, culturas e diversidades, Teresina, v. 3, n. 1, p. 53-73, Jan./Abr. 
hierárquica na qual o autor destaca três partes. A estética que ocuparia a mais importante posição, a parte "harmônica ou de composição", ocupando a posição intermediária, e aquela que ocuparia a posição inferior nessa hierarquia, isto é, a parte "material ou prática", que limitar-se-ia ao conhecimento e ao emprego técnico, "mecânico" e "correto" de todos os caracteres da escrituração musical (MACHADO, 1855, p. 248-249).

No bojo dessa valorização teórica e estética é preciso destacar ainda importância que a questão ético-pedagógica vai ter também entre conjunto de ideias tratadas por Raphael Coelho Machado, ao se considerar, por exemplo, o verbete "INFLUÊNCIA DA MÚSICA". O que fica evidente quando o autor enfatiza a influência histórica que a música vem exercendo "sobre a civilização, os costumes, a paixão e o heroísmo militar"; a sua função para "abrandar o caráter do homem”; o papel da sua "educação moral e intelectual" para despertar "sentimentos de benevolência e de amor"; e o seu poder para "aliviar fadigas", "excitar a coragem nos campos de batalha", "celebrar triunfos" e "homenagear os vencedores", bem como revestir "de pompa e grandeza as cerimônias religiosas".

Diante de tantos atributos gerais, pensando especificamente nas finalidades pedagógicas que estariam associadas ao projeto de elaborar e publicar o dicionário e, sobretudo, no seu papel como parte de um projeto de institucionalização do ensino de música, é notório perceber que o autor conclui então o verbete pondo em destaque exatamente a importância da música para a "educação da mocidade", para além das suas finalidades enquanto uma formação profissional. Uma conclusão que se encerra se exaltando mais uma vez o suposto potencial dessa arte enquanto "um poderoso meio de moralidade"; um "meio" extremamente precioso para "estabelecer a harmonia entre os pensamentos e os sentimentos, para fortificar o amor da ordem e do belo e para animar este instinto a que se chama Amor pátrio" (MACHADO, 1855, p. 92-93). Retomando, assim, a concepção clássica da música como um importante meio para desenvolver uma educação que deveria estar a serviço, respectivamente, da ética, da disciplina, da estética e, também, da política (FUBINI, 2008).

\section{Conclusões e considerações finais}


Em termos de conclusões específicas, é preciso ter em vista, como já dito, que esse ensaio constitui-se como um desdobramento de outros trabalhos já realizados pelo autor que tiveram como foco a institucionalização do ensino de música no Rio de Janeiro, durante o século XIX. A partir desse espectro mais amplo, pode se compreender então a publicação deste dicionário como parte dos esforços para consolidar um projeto específico de institucionalização do ensino de música articulado à formalização de uma dada cultura musical e à afirmação do seu papel como pedagogia.

De maneira geral, a intenção pedagógica que envolveu a realização desse dicionário já estava anunciada, aliás, na própria introdução do livro, quando o autor afirma a sua "expectativa de fazer algum serviço aos que se dedicam à Música, oferecendo-lhes um dicionário que, apesar do justo receio de não ser completo e abundar em faltas, poderá todavia ser de muito proveito aos principiantes" (MACHADO, 1855, p. VI-VII). Posição, por sua vez, reconhecida pela imprensa, como pode ser observada, por exemplo, em nota publicada no Jornal do Commercio recomendando o dicionário "a todos os amadores desta admirável arte e que (à semelhança dos povos mais civilizados) forma hoje uma parte importante da educação da mocidade brasileira [...]" (Idem, p. XII, grifo nosso).

Considerações que permitem articular o programa institucional associado ao ensino de música no contexto histórico em foco, ao desenvolvimento de um "regime de amadorismo" e às reflexões sobre a cultura musical como pedagogia e, no caso do dicionário, sobre a afirmação da pedagogia musical como cultura. O que se torna evidente ao se analisar os verbetes selecionados e constatar a importância que a aprendizagem da escrituração e da teoria musical vai assumir como um pressuposto básico para a difusão e a consagração de determinados valores estéticos, éticopedagógicos e, também, profissionais da música. Nessa perspectiva, os estudos e a educação passariam a exercer então um papel determinante, tanto para aqueles que faziam da música uma "ocupação", quanto para os "curiosos" e os diletantes, distinguindo-os, assim, daqueles que a exerciam apenas como um ofício "manual" e "mecânico", ou, ainda, daqueles que tinham-na como um passatempo de caráter absolutamente prático, a despeito de quaisquer fundamentações teóricas e "gramaticais". 
Quanto às considerações gerais, espera-se que esse ensaio possa contribuir de alguma forma com a ampliação e o aprofundamento da área de estudos sobre a História da Educação Musical, chamando a atenção para a importância de se perceber e analisar as diferentes articulações históricas entre o ensino de música, os sistemas escolares e os sistemas culturais extraescolares, especificamente a partir da compreensão dos diferentes papéis da cultura musical como pedagogia e da pedagogia musical como cultura. O que pode alargar as possibilidades de contribuição da História da Educação Musical tanto com a História da Educação, em temos mais gerais, quanto com o próprio campo da Educação Musical como um todo, pensando, por exemplo, sobre as relações históricas dessas instâncias culturais e pedagógicas com a formação docente, as definições do currículo e das práticas de ensino de música; sobre as relações entre o capital cultural dos docentes de música e as suas concepções de ensino, os seus posicionamentos político-pedagógicos e a afirmação da sua identidade profissional; ou, ainda, pensando sobre como se processa, em termos sócio-históricos, as articulações, as apropriações e as ressignificações de determinadas culturas e pedagogias musicais, entre as escalas internacionais, nacionais, regionais e locais, conforme o contexto, a época e o recorte espacial e temporal.

\section{Referências}

ALENCASTRO, Luiz Felipe de. Vida Privada e ordem privada no Império. In: NOVAIS, Fernando Adauto (coordenador geral da coleção), ALENCASTRO, Luiz Felipe de (organizador do volume). História da vida privada: Império. São Paulo: Companhia das Letras, 2008, p. 11-93.

ALLEN, Warren Dwight. The "Development" and "Progress" of Music. In: ALLEN, W. D. Philosophies of Music History: a study of general histories of music 1600 - 1960. New York: Dover Publications, 1962, p. 228-260.

AMATO, Rita de Cássia Fucci. O piano no Brasil: uma perspectiva histórico-sociológica. In: Anais do XVII congresso da Associação Nacional de Pesquisa e Pós-graduação em Música, Trabalhos: Musicologia, 2007.

BOUISSOU. Sylvie. La notation musical aux époque baroque et classique. In: BOUISSOU. Sylvie; GOUBAULT, Christian; Bousser, Jean-Yves. Histoire de la notation: de l'époque baroque à nos jours. Paris: Minerve, 2005, p. 13-106.

CAMPOS, Rémy. Essay. In: Le Conservatoire de Paris: une institution en questions. Paris: L'oeil d'or, 2016, p. 11-79. 
DUBET, François. Le Declin de l'Institution. Paris: Éditions du Seuil, 2002.

ELIAS, Norbert. Mozart: sociologia de um gênio. Rio de Janeiro. Jorge Zahar, 1995.

FUBINI, Enrico. Estética da música. Lisboa: Edições 70, 2008.

GARCIA, Gilberto Vieira. "Tão sublime como encantadora Arte" - as Aulas e os "Mestres de Música no Imperial Collegio de Pedro II (1838-1858). [Dissertação de Mestrado] Rio de Janeiro: Programa de Pós-Graduação em Educação, Pontifícia Universidade Católica (RJ), 2014.

GARCIA, G. V.. Música: o estudo, o ensino, a docência, entre formuladores e mestres - Rio de Janeiro (1838-1899). [Tese de Doutorado]. Rio de Janeiro: Programa de Pós-Graduação em Educação, Universidade Federal do Rio de Janeiro (PPGE/UFRJ), 2018.

GARCIA, G. V. Araújo Porto Alegre e a música no Brasil Império: filosofia, história, ideias e projetos. In: Revista do IHGB, ano 180, n. 480, p. 121-148, maio/agosto 2019.

GOEHR, Lydia. The historical approach. In: GOEHR, L. The Imaginary Museum of Musical Works: an essay in the philosophical of music. New York: Oxford University Press, 2007, Part II, p. 89-286.

GUMPLOWICZ, Philippe. Les travaux d'Ofphée: 150 ans de vie musicale amateur en France Harmonies-Chorales-Fanfares. Paris: Aubier, 1987.

HENNION, Antoine; FAUQUET, Jöel-Marie. La grandeur de Bach - l'amour de la musique en France au XIX siècle. Paris: Fayard, 2000.

MACHADO, Raphael Coelho. Diccionario Musical, $2^{\mathrm{a}}$ edicção augmentada pelo seu autor. Rio de Janeiro: Typ. Do Commercio de Brito e Braga - Travessa do Ouvidor n.14, 1855.

MAGALDI, Cristina. Music for the Elite: Musical Societies in Imperial Rio de Janeiro. Latin American Music Review / Revista de Música Latinoamericana. University of Texas Press, v. 16, n. $1,1995$.

MELO, Victor Andrade de. Educação do corpo - bailes no Rio de Janeiro do século XIX: o olhar de Paranhos. Educação e Pesquisa. São Paulo, v. 40, n. 3, p. 751-766, jul./set. 2014.

MENGER, Pierre-Michel. Comment analyser la grandeur artistitque? Beethoven et son genie. In: MENGER, P. Le travail créateur: s'accomplir das l'incertain. Paris: Seuil/Gallimard, 2009, Chapitre 7, p. 367-427.

NÓVOA, Antônio. Para o estudo sócio-histórico da gênese e desenvolvimento da profissão docente. Teoria e Educação. Porto Alegre, nº 4, 1992, p. 109-139.

NUNES, José Horta. Dicionários: história, leitura e produção. Revista de Letras da Universidade Católica de Brasilia. v.3, n. 1/2 - ano III - dez/2010, p. 6-21.

PORTO-ALEGRE, Manuel Araújo. Sobre a Música. In: NITHEROY, REVISTA BRASILIENSE - SCIENCLAS, LETTRAS, E ARTE. Paris: Dauvin et Fontaine, Libraires, Tomo Primeiro, No $1^{\circ}$, p. 160-183. 
SILVA, Tomaz Tadeu. A cultura como pedagogia. A pedagogia como Cultura. In: SILVA, T. T. Documentos de identidade. Uma introdução às teorias do currículo. BH: Autêntica, 2004, p. 139-142.

SQUEFF, Leticia. O Brasil nas letras de um pintor. São Paulo: Editora da Unesp, 2004.

RECEBIDO: 01/02/2021

APROVADO:03/04/ 2021
RECEIVED: 01/02/2021

APPROVED: 03/04/ 2021
RECIBIDO: 01/02/ 2021

APROBADO: 03/04/ 201 